\title{
Development of Composite Flour Cookies to Curb Anaemia
}

\section{Proximate and Nutritional Analysis of Composite Flour for Product Development And Its Sensory Evaluation}

\author{
Shraddha Saroj \\ Junior Research Fellow, Food and Nutrition, Department of \\ Home Science \\ Banaras Hindu University \\ Varanasi, U.P., India
}

\author{
Shruthi M S \\ Lecturer, Food Science and Nutrition, \\ Bioscience Department \\ Mangalore University \\ Mangalore, Karnataka., India
}

\author{
Kalpana Gupta \\ Professor, \\ Department of Home Science, \\ Banaras Hindu University, \\ Varanasi, U.P., India
}

\begin{abstract}
Present investigation was carried out to develop the composite flour made by mixing wheat (Triticum aestivum), little millet (Panicum sumatrense), moth bean (Vigna aconitifolia) and mango ginger (Curcuma amada). These ingredients were processed by soaking, sprouting, drying at $\left(35^{\circ} \mathrm{C}\right)$ and roasting except mango ginger which was peeled, sliced and dried at $60^{\circ} \mathrm{C}$. All these ingredients were powdered and composite flour was formulated in two ratios: $R_{1}(50: 20: 20: 10)$ and $R_{2}$ (30:30:30:10) containing wheat, little millet, moth bean and mango ginger, respectively. The proximate and nutritional analysis showed that $\mathbf{R}_{2}$ contains a higher amount of ash $(3.69 \%)$, fibre $(2.78 \%)$ and iron content $(17.01 \mathrm{mg} / 100 \mathrm{~g})$; hence it was considered for product development. Vanilla and Chocolate flavoured cookies were developed and subjected to sensory evaluation (using the 9-point hedonic scale). All the cookies had sensory scores above ' 8 ' showing that they were either 'liked very much' or 'liked extremely' (9) by all the panel members. The overall acceptability of chocolate flavoured cookies was significantly higher $(\mathbf{p}<0.05)$ than the vanilla flavoured cookies. Therefore, the regular consumption of iron rich cookies can tackle the problem of anaemia to some extent.
\end{abstract}

Keywords - Wheat (Triticum aestivum); Little millet (Panicum sumatrense); Mango ginger (Curcuma amada); Moth Bean (Vigna aconitifolia), Cookies

\section{INTRODUCTION}

Nutritional anaemia is a syndrome caused by malnutrition. WHO has defined it as 'a condition in which the haemoglobin content of the blood is lower than normal as a result of deficiency of one or more essential nutrients, regardless of the cause of such deficiency'. By far, the most common cause of nutritional anaemia is iron deficiency, and less frequently folate or vitamin B ${ }_{12}$ (Park, 2017). Iron deficiency can arise either due to inadequate intake or poor bioavailability of dietary iron or due to excess losses of iron from the body. Although most habitual diets contain seemingly adequate amounts of iron, only a small amount (less than 5\% is absorbed). This poor bioavailability is considered to be a major reason for widespread iron deficiency (Park, 2017).

Anaemia is a major public health problem in India which affects over half of the population in almost all age groups (NITI Aayog, 2019). The more severe the anaemia, the greater is the reduction in work performance, and thereby productivity. This has great significance on the economy of the country. Physical and cognitive losses due to iron deficiency anaemia (IDA) costs the developing countries up to $4.5 \%$ loss in GDP per annum, which is 1.18 percent of GDP in India, thereby stalling social and economic development. Women below the reproductive age group are most vulnerable and this further gets aggravated during pregnancy, which has a negative impact on maternal, foetal, and new-born health. The prevalence of anaemia amongst pregnant women has consistently remained around $50 \%$ over the last four decades. This projected a negative $-26.51 \%$ impact of the program, causing 5.25 days lost per person. Therefore, if a pregnant woman is suffering from anaemia caused due to iron deficiency then, she is likely to lose approximately 5.25 days of her life. The cost-effective calculations revealed that it could cost approximately $\$ 75.97$ (5063.47 INR) for each DALY (disability-adjusted life year) lost due to iron deficiency anaemia during pregnancy. This loss is huge when 
calculated for the entire population of pregnant women in India. (NITI Aayog, 2019).

The need for strategic development in the use of inexpensive local resources in the production of staple foods has been promoted by organizations such as the Food and Agricultural Organization (FAO) and the United Nations refugee feeding programs (Awogbenja and Ndife, 2012). This led to the initiation of the composite flour program, the objective of which was to seek ways of substituting flours, starches and protein concentrates from indigenous crops, for as much wheat as possible in baked products. Flour made by blending or mixing varying portions of more than one non wheat flour with or without wheat flour and used for the production of leavened or unleavened baked or snacked products that are traditionally made from wheat flour and increase the essential nutrients in the human diet is called composite flour (Chandra, Singh, \& Kumari, 2015).

Formulation of composite flour may be considered as an important tool for enriching any food product. Thus, the formulation of composite flour using whole wheat (cereal), moth bean (pulse), mango ginger (tuber), little millet (coarse grain) and sesame (oil seed) was considered in this project. Wheat is the most important staple food crop for more than one-third of the world population and considered a good source of protein, minerals, B-group vitamins and dietary fibre (Kumar et al., 2011). Among the food grains, millets are the cheapest and nutritionally wholesome food for people of all age groups. Supplementation of cereal-based products with millets has become increasingly popular due to its nutritional and economic advantages (Preethi \& Mohankumar, 2014). Mango ginger (Curcuma amada) looks exactly like ginger but tastes like raw mango, hence the name Aam Adrak. The major chemical components include starch, phenolic acids, volatile oils, curcuminoids and terpenoids. (Policegoudra, Aradhya, \& Singh, 2011). Sesame (Sesamum indicum) has high nutritional value due to the significant amount of dietary fibre, protein, natural antioxidants, unsaturated fatty acids, vitamins, and mineral constituents present in its composition (Anilakumar, Pal, Khanum, \& Bawa, 2010).

Cookies available in the market are usually made from refined wheat flour which lacks essential nutrients and fibre. Therefore, this study intends to produce nutrient-rich and affordable cookies which are made from composite flour and will help to tackle iron deficiency as well as undernutrition to a certain extent.

\section{MATERIALS AND METHODS}

\subsection{Collection of ingredients}

The raw materials i.e., wheat (Triticum aestivum), moth bean (Vigna aconitifolia) and little millet (Panicum sumatrense) (1 kg each) were purchased from a nearby supermarket of Mangalore, Karnataka, India. Mango ginger (Curcuma amada) was collected from Puttur, Karnataka.

\subsection{Processing of raw material}

Wheat, moth bean and little millet (1/2 kg each) were washed thoroughly with water and then kept for soaking overnight (12 hours) after which the water was drained off and the ingredients were rinsed again. Then half $\mathrm{kg}$ of wheat was kept in a moist cotton cloth for sprouting. Wheat took 48 hours for proper sprouting whereas moth bean took only 24 hours.

Now sprouted wheat (SW), sprouted moth bean (SMB) and soaked little millet (SLM) were kept for sun-drying at a temperature of $35^{\circ} \mathrm{C}$, wind velocity of $12.2 \mathrm{~km} /$ hour for 8 hours as depicted in fig 1 . Mango ginger was peeled, cut into thin slices and kept for drying in a hot air oven at $60^{\circ} \mathrm{C}$ for 4 hours. Once all ingredients dried, they all were roasted for 10 minutes at the medium flame to further reduce its moisture content. When all four ingredients have cooled, they were grounded in Panasonic mixer-grinder into a very fine powder and allowed to cool for some time. Finally, each ingredient was packed in a plastic airtight container.
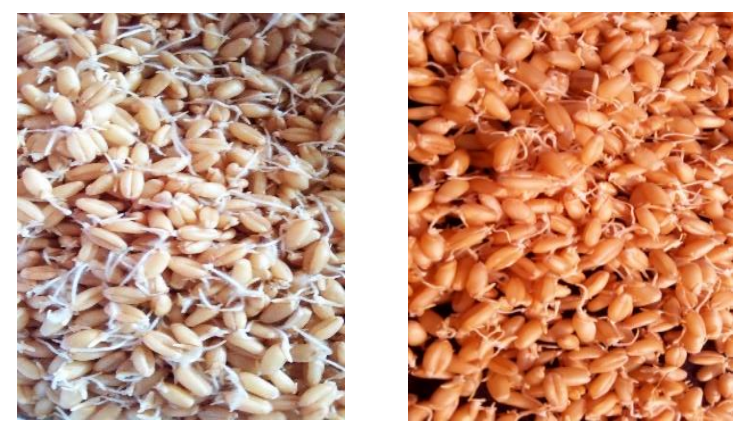

a) Wheat (sprouted and sundried)
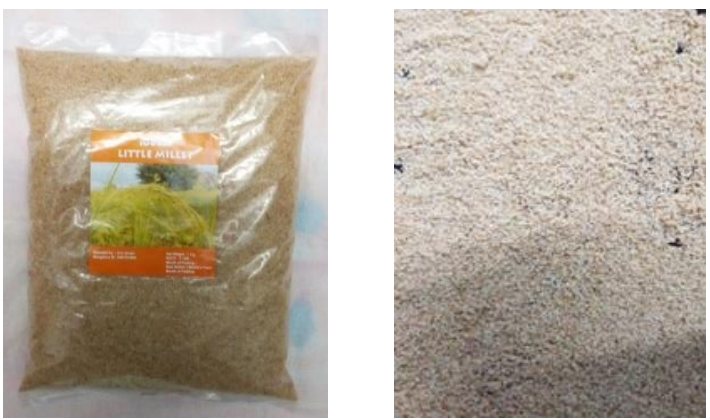

b) Little millet (sundried)
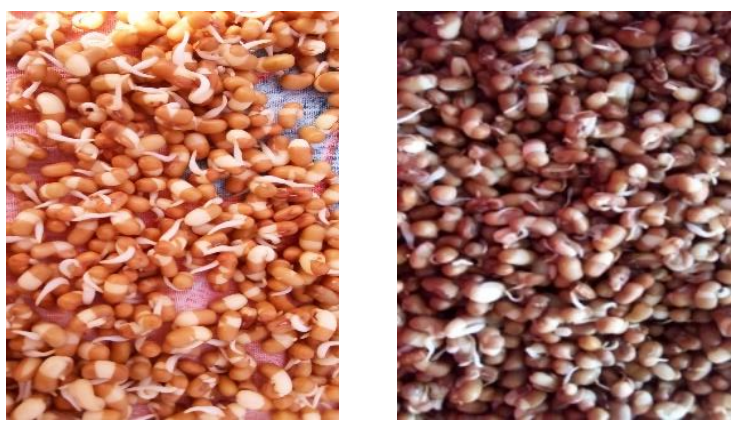

c) Moth bean (sprouted and sundried) 


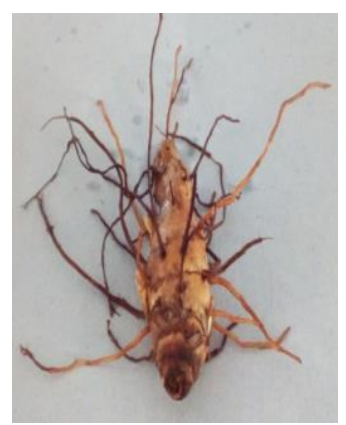

d) Mango ginger

Fig 1: Showing ingredients used for composite flour development

\subsection{Development of composite flour}

After processing, all ingredients were used for the formulation of composite flour. The blended ratios used for the study were 50:20:20:10 $\left(\mathrm{R}_{1}\right)$ and 30:30:30:10 $\left(\mathrm{R}_{2}\right)$ for wheat (SW), moth bean (SMB), little millet (SLM) and mango ginger respectively.

\subsection{Nutritional analysis}

\subsubsection{Estimation of total moisture content}

$3 \mathrm{~g}$ of the sample was weighed in a previously dried petri plate and placed in the oven for 75 minutes. The time was recorded from the moment the oven attained $120^{\circ} \mathrm{C}$ after the dishes have been placed. After 75 minutes, the samples were taken out of the oven, cooled and weighed. The sample was placed in an oven at half-hour intervals until a constant weight was achieved. The moisture content was calculated using the standard formula and expressed in percentage.

$$
\text { Moisture Content }(\%)=\frac{\begin{array}{c}
\text { (Initial weight }- \\
\text { Final weight })
\end{array}}{\text { Initial weight }} \times 100
$$

\subsubsection{Estimation of total ash content}

$1 \mathrm{~g}$ of the sample was weighed accurately into a crucible (which was previously heated to about $600^{\circ} \mathrm{C}$ and cooled). The crucible was placed on a clay pipe triangle and heated first over a low flame till all the material was completely charred, followed by heating in a muffle furnace for about 3-5 hours at $600^{\circ} \mathrm{C}$. It was then cooled and weighed. To ensure completion of ashing, the crucible was again heated in a muffle furnace for half an hour, cooled and weighed. This was repeated till two consecutive weights were obtained and the ash was almost white or greyish white. The total ash content was calculated using the standard formula and expressed in percentage.

(weight of crucible and ash weight of crucible)

$$
\operatorname{Ash}(\text { wet })(\%)=\frac{}{\text { (weight of crucible and sample }-} \times 100(2)
$$

$$
\operatorname{Ash}(\text { dry })(\%)=\frac{\text { Percentage of ash (wet) }}{(100-\text { percentage of moisture })} \times 100
$$

\subsubsection{Estimation of crude fibre}

The total crude fibre was determined by following the Sadasivam and Manickam (2016). For estimation of crude fibre, $2 \mathrm{~g}$ of the sample was boiled with $200 \mathrm{ml}$ of sulphuric acid for 30 minutes. It was filtered through a muslin cloth and washed with boiling water until the washings are no longer acidic. Then it was boiled with $200 \mathrm{ml}$ of sodium hydroxide for 30minutes. It was again filtered through a muslin cloth and washed with three $50 \mathrm{ml}$ portions of water ensuring it is no longer alkaline. The residue was removed and transferred to the ashing dish (pre-weighed dish $\mathrm{w}_{1}$ ). The residue was dried at $120 \pm 2^{\circ} \mathrm{C}$ for 2 hours. Cooled and weighed $\left(\mathrm{w}_{2}\right)$. It was ignited at $600 \pm 15^{\circ} \mathrm{C}$ for 30 minutes. Cooled and reweighed $\left(w_{3}\right)$. The percentage of crude fibre in the ground sample was calculated using the standard formula.

loss in weight on ignition

$$
\left(\mathrm{W}_{2}-\mathrm{W}_{1}\right)-\left(\mathrm{W}_{3}-\mathrm{W}_{1}\right)
$$

Crude fibre $(\%)=$

\section{Weight of sample}

\subsubsection{Estimation of iron}

$5 \mathrm{~g}$ of powdered sample was weighed and taken in a porcelain crucible and heated first over a flame till all the material was completely charred. It was followed by heating in a muffle furnace for about $3-5$ hours at $600^{\circ} \mathrm{C}$. Then the sample was cooled and ash was collected. The obtained ash was moistened with $1 \mathrm{ml}$ distilled water. $5 \mathrm{ml}$ of $\mathrm{HCl}$ was added, evaporated to dryness on boiling water bath and this step was repeated. Then added $4 \mathrm{ml} \mathrm{HCl}$ and $1 \mathrm{ml}$ distilled water and warmed. It was then filtered into $50 \mathrm{ml}$ volumetric flask cooled and made up the volume. The aliquots were used for estimation of iron in ash solution. $1 \mathrm{ml}-5 \mathrm{ml}$ of standard solutions were pipetted out into a series of test tubes. The volume was made up to $5 \mathrm{ml}$ by adding distilled water. Blank is prepared by adding $5 \mathrm{ml}$ of distilled water in a test tube. The test was prepared by taking $1 \mathrm{ml}$ of test solution in the test tube and made up to $5 \mathrm{ml}$ using distilled water. Then $30 \%$ of sulphuric acid was added to all the test tubes making the volume up to $6 \mathrm{ml}$. Thereafter, $1 \mathrm{ml}$ of Potassium persulfate solution and $1.5 \mathrm{ml}$ of Potassium thiocyanate was added to all the test tubes and then incubated for 20minutes at room temperature. The intensity of the standard is observed at $540 \mathrm{~nm}$ against blank. The amount of iron (ferric form) in the sample was calculated using the standard curve and expressed as $\mathrm{mg} / 100 \mathrm{~g}$ of the sample.

\subsection{Preparation of cookies}

Developed composite flour was used for the production of cookies according to the Inyang, Effiong, \& Nyah, 2018 with slight modifications using the ingredients mentioned in table 1 . 
Table 1: Quantity of ingredients used for the production of vanilla and chocolate flavoured cookies

\begin{tabular}{|l|c|c|}
\hline \multicolumn{1}{|c|}{ Ingredients used } & Vanilla flavour & Chocolate flavour \\
\hline 1) Sprouted wheat (SW) & $90 \mathrm{~g}$ & $90 \mathrm{~g}$ \\
\hline 2) Sprouted moth bean (SMB) & $90 \mathrm{~g}$ & $90 \mathrm{~g}$ \\
\hline 3) Soaked little millet (SLM) & $90 \mathrm{~g}$ & $90 \mathrm{~g}$ \\
\hline 4) Mango ginger & $30 \mathrm{~g}$ & $30 \mathrm{~g}$ \\
\hline 5) Butter & $120 \mathrm{~g}$ & $120 \mathrm{~g}$ \\
\hline 6) Sugar & $70 \mathrm{~g}$ & $70 \mathrm{~g}$ \\
\hline 7) Baking Powder & $2 \mathrm{~g}$ & $2 \mathrm{~g}$ \\
\hline 8) Vanilla Essence & $2-3$ (drops) & - \\
\hline 9) Dark Chocolate Chunks & - & $22 \mathrm{~g}$ \\
\hline
\end{tabular}

For preparation of cookies, butter taken at room temperature was mixed with sugar and whisked continuously until it attains a creamy texture by incorporating air. About 23 drops of vanilla essence were added and mixed properly. Then a small amount of composite flour was added along with a pinch of baking powder and folded. Finally, complete flour was added and appropriately folded to get the right consistency of the dough. The same method was followed for the development of chocolate flavoured cookies but in place of vanilla essence, dark chocolate chunks were used. If required, the dough can be kneaded for proper mixing and binding.

Once the dough is ready vanilla flavoured cookies were cut into small pieces and given round shape manually and finally, sesame seeds were sprinkled on it. The chocolate flavoured dough was also cut into small piece and flattened with the help of rolling pin and rolling board into a circle and then cut into a diamond shape with the help of knife manually. They were sprinkled similarly with sesame seeds. Now both the cookies were placed in separate baking trays and kept in a pre-heated oven at $180^{\circ} \mathrm{C}$ for 16 minutes. After 16 minutes it was taken out and kept for cooling as they were soft and hardens on cooling.

\subsection{Sensory evaluation of cookies}

Forty members were selected from the Food Science and Nutrition Department after their consent for carrying out sensory evaluation. They were initially trained- meaning of each attribute was explained to the panelists to avoid any misinterpretation (Handa, Goomer, \& Siddhu, 2012). The cookies (both vanilla and chocolate flavour) were prepared one day before performing the sensory evaluation and kept in airtight containers at room temperature. The division of panel members is depicted in figure 2 .

One group of students from the Food Science and Nutrition Department (I and II years M.Sc.) and the other group comprised the working class from the same department (teaching faculty). All evaluations were done in Food Science and Nutrition lab in white light. Each panel member was provided both, vanilla and chocolate flavoured cookies in separate plates along with distilled water to clear their mouth during evaluation. A 9-point hedonic scale was used for sensory evaluation (Nasir et al., 2010, Nwakalor, 2014). For subsequent quantitative and statistical analysis, the verbal categories were assigned numerical values, ranging from 'like extremely' as '9' to 'dislike extremely' as ' 1 '. Ranking of 9point hedonic scale is as follows, 9-like extremely, 8- like very much, 7- like moderately, 6- like slightly, 5- neither like nor dislike, 4- dislike slightly, 3- dislike moderately, 2-dislike very much, 1- dislike extremely (Ho \& Latif, 2016). Sensorial attributes taken into consideration were appearance, colour, aroma, flavour, texture, mouthfeel, chewiness, and after taste. Panellists were also asked to give points for overall acceptability of cookies.

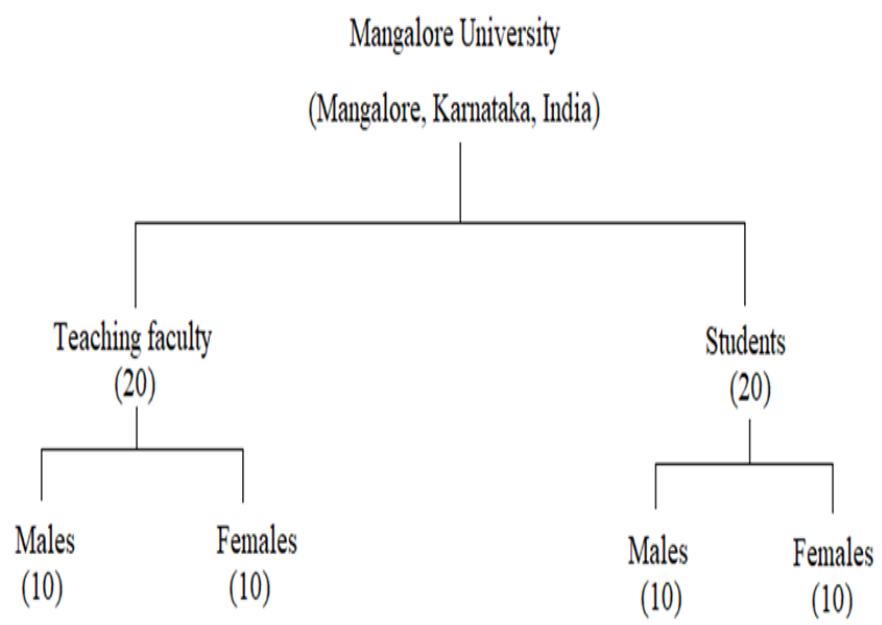

Fig 2: Showing the division of panel members

\section{RESULT AND DISCUSSION}

\subsection{Processing of ingredients}

In the present investigation, processing of selected ingredients was very beneficial in enhancing their nutritional quality. Also reported by Khokhar \& Chauhan (2006) soaking of moth bean played an essential role in reducing the phytic acid content and sprouting, had saponin reducing effect. Moreover soaking, sprouting and cooking of moth bean together played an important role in inhibiting the activity of trypsin inhibiter. Germination of soaked moth bean played an important role in improving the digestibility of protein and starch as cited by Negi, Boora, \& Khetarpaul (2001). Similarly processing of little millet showed better nutraceutical properties such as increase in total phenolic, flavonoid and phytic contents as observed by Pradeep \& Guha (2011). 


\subsection{Development of composite flour}

The quality and acceptability of any product is directly related to the kind of base material used and adoption of precise methodology for their preparation. According to Hussein, Hussein, \& El-Damohery (2006), flour is the main criterion that makes the product likeable. In this experiment, composite flour was prepared by using SW (cereal), SMB (pulse), SLM (millet), and mango ginger (tuber) are taken in two different ratio's $\mathrm{R}_{1}(50: 20: 20: 10)$ and $\mathrm{R}_{2}$ (30:30:30:10) respectively.

Development of composite flour is beneficial as it enhances the nutritional content and improves the digestibility of the final product (Chandra, Singh, \& Kumari, 2015). In this case, the addition of moth bean flour (an important source of lysine) to the wheat flour (which contains methionine) played an essential role in improving the quality of protein. Same concept is followed in Indian diets where 'khichdi' usually made by mixing rice (cereal) and pulses of different kinds to

obtain a wholesome good quality protein rich final product with low cost and high sensory acceptability. Mango ginger (tuber) showed medicinal properties such as anti-bacterial, anti-fungal, anti-ageing, antioxidant, anti-inflammatory, antiallergic, platelet aggregation inhibition activity and analgesic activity. Therefore, addition of mango ginger in the composite flour might have improved the medicinal properties.

\subsection{Proximate and nutritional analysis of composite flour}

The proximate and nutritional analysis of both the ratios of composite flour was done using standard protocols. The mean values obtained for different parameters are given in the table 2 .

Table 2: Proximate and nutritional analysis of $R_{1}$ and $R_{2}$ of the composite flour

\begin{tabular}{|l|l|l|}
\hline Proximate Composition & $\mathrm{R}_{1}(50: 20: 20: 10)$ & $\mathrm{R}_{2}(30: 30: 30: 10)$ \\
\hline Total Moisture (\%) & 2.55 & 3.51 \\
\hline Total Ash (\%) & 2.91 & 3.69 \\
\hline Crude Fiber (\%) & 2.07 & 2.78 \\
\hline Iron (\%) & 13.37 & 17.01 \\
\hline
\end{tabular}

The values are means of triplicates

It is important to know the proximate composition of flour for the development of new formulations in bakery products (Varastegani, Zzaman, \& Yang, 2015). It was observed that the average moisture content in $\mathrm{R}_{2}$ was higher $(3.51 \%)$ than $\mathrm{R}_{1}(2.55 \%)$. Low moisture content is beneficial as it ensures a long shelf life of the food product (Hussein et al, 2006). The average ash content of $\mathrm{R}_{2}$ was higher (3.69\%) than $\mathrm{R}_{1}$ i.e., $2.91 \%$. High ash content can be attributed to an increase in mineral content (Hussein et al, 2006) as the proportion of moth bean and little millet increases and that of wheat decreases. As stated by Nambi, Eganathan, \& Philip (2012) little millet is an important source of minerals like iron, calcium, zinc, magnesium, phosphorus and potassium.

The average crude fibre content was higher in $\mathrm{R}_{2}(2.78 \%)$ than $\mathrm{R}_{1}(2.07 \%)$. Higher crude fibre is an indication of its potential application in the development of value-added healthy food (Varastegani et al., 2015). The average iron content of $\mathrm{R}_{2}$ was higher i.e., $17.01 \%$ than $\mathrm{R}_{1}(13.37 \%$ ) which fulfils the primary purpose of development of iron-rich composite flour. Thus, $\mathrm{R}_{2}$ was chosen for product development as it showed better nutritional properties.

\subsection{Product development}

Snacks like cookies are liked by all as they are consumed by every age group, hence cookies were chosen to be produced from the composite flour. Vanilla and chocolate flavours were selected as they are acceptable and liked by majority of population around the world, thus cookies were developed from the selected composite flour ratio $\left(\mathrm{R}_{2}\right)$, by following the procedure as mentioned in the material and methods sub-heading 2.5.1. Both types i.e., vanilla and chocolate flavours are depicted in figure 3.
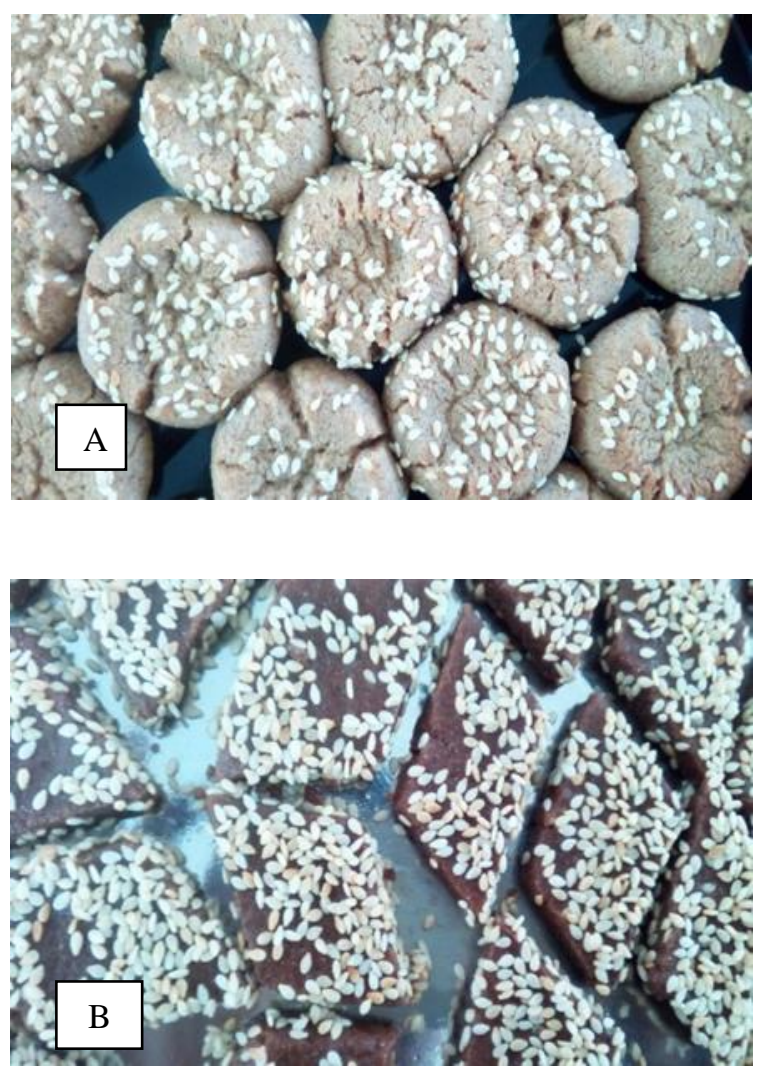

Fig (3) Showing (A) vanilla and (B) chocolate flavoured composite flour cookies.

\subsection{Sensory evaluation and overall acceptability of cookies}

\subsubsection{Vanilla flavoured cookies}

Detailed sensory evaluation of vanilla flavoured cookies as presented in table 3 showed that the appearance of the vanilla cookies was 'liked extremely' by the male students 
$(8.8 \pm 0.6324)$ whereas it was 'liked very much' by the female students $(8.3 \pm 0.6749)$ of the Food Science and Nutrition Department (FSN). The vanilla cookies have appealing appearance hence, aroused interest among the panel members. Most of them observed that their appearance was similar to commercially available cookies.

The light cream colour of the vanilla cookies was 'liked extremely' by the male teaching faculty $(8.1 \pm 0.4830)$ and it was 'liked very much' by the male students $(8.1 \pm 0.3162)$. The flavour of the cookies was developed due to the addition of vanilla essence and also due to the caramelization of sugars (Singh, Riar, \& Saxena, 2008) which was 'liked very much' by all the panel members.

After baking, the cookies increased in size probably because of the addition of baking powder and had cracks over its surface with crispy texture which was 'liked very much' by the male faculty members $(8.3 \pm 0.6749)$ of the FSN department. Maximum points were given by male students $(9 \pm 0)$ for the mouthfeel of vanilla cookies, whereas it was 'liked very much' $(8 \pm 0.6667)$ by the male teaching faculty.

The female students gave $8.5 \pm 0.5270$ points to the chewiness whereas male students and male teachers gave almost the same points i.e., $8 \pm 0.4714$ and $8 \pm 0.6667$ respectively. The female students preferred the aftertaste of the vanilla cookies $(8.9 \pm 0.3162)$ whereas it was liked very much by the female teaching faculty members $(7.9 \pm 0.3162)$ of the FSN department, Mangalore University.

\subsubsection{Chocolate flavoured cookies}

Perusal of the data given in table 4 for sensory evaluation of chocolate flavoured cookies showed that the female teaching faculty liked its appearance and gave maximum points $(9 \pm 0)$, whereas the appearance was liked very much by the female students. The colour of the cookies is an important factor for their acceptability which was developed due to the addition of chocolate chunks and was 'liked extremely by the male teaching faculty $(9 \pm 0)$.

Presence of baked sesame seeds and chocolate chunks gave a pleasant aroma to the cookies which was liked extremely by the female teaching faculty $(8.6 \pm 0.5163)$. The flavour of the cookies was also developed due to the Maillard reaction between reducing sugars and protein (Dhingra \& Jood, 2000) and was almost equally liked by the male students and female teachers.

Texture is the sensory manifestation of the structure of food and how the structure reacts to the applied force (Guinard \& Mazzucchelli, 1996), and is one of the most critical parameter connected to product quality. Mouthfeel refers to how the product feels in the mouth (initial bite) (Jemziya \& Mahendran, 2015). Minimum points were given to the chewiness of the cookies by male students. The aftertaste of the cookies was 'liked extremely' by the female teachers whereas it was 'liked very much' by the male teachers.

Table 3: Sensory evaluation of vanilla flavoured cookies

\begin{tabular}{|l|l|l|l|l|}
\hline Sensory Attributes & Male Students & Female Students & Male Teachers & Female Teachers \\
\hline Appearance & $8.8 \pm 0.6324$ & $8.3 \pm 0.6749$ & $8.7 \pm 0.4830$ & $8.3 \pm 0.6749$ \\
\hline Colour & $8.1 \pm 0.3162$ & $8.5 \pm 0.5270$ & $8.7 \pm 0.4830$ & $8.5 \pm 0.5270$ \\
\hline Aroma & $8.3 \pm 0.4830$ & $8.1 \pm 0.5676$ & $7.9 \pm 0.7378$ & $8.1 \pm 0.5676$ \\
\hline Flavour & $8.4 \pm 0.6992$ & $8.2 \pm 0.6324$ & $8.3 \pm 0.6749$ & $8.2 \pm 0.6324$ \\
\hline Texture & $8.0 \pm 0.8165$ & $8.1 \pm 0.7378$ & $8.3 \pm 0.6749$ & $8.1 \pm 0.7378$ \\
\hline Mouthfeel & $9.0 \pm 0.0000$ & $8.1 \pm 0.5676$ & $8.0 \pm 0.6667$ & $8.1 \pm 0.5676$ \\
\hline Chewiness & $8.0 \pm 0.4714$ & $8.5 \pm 0.5270$ & $8.0 \pm 0.6667$ & $8.5 \pm 0.5270$ \\
\hline Aftertaste & $8.6 \pm 0.6992$ & $8.9 \pm 0.3162$ & $8.1 \pm 0.5676$ & $8.9 \pm 0.3162$ \\
\hline
\end{tabular}

The values are means of ten replicates \pm standard deviation.

Table 4: Sensory evaluation of chocolate flavoured cookies

\begin{tabular}{|c|c|c|c|c|}
\hline Sensory Attributes & Male Students & Female Students & Male Teachers & Female Teachers \\
\hline Appearance & $8.6 \pm 0.5163$ & $8.5 \pm 0.5270$ & $8.8 \pm 0.4216$ & $9.0 \pm 0.0000$ \\
\hline Colour & $8.5 \pm 0.5270$ & $8.6 \pm 0.5163$ & $9.0 \pm 0.0000$ & $8.9 \pm 0.3162$ \\
\hline Aroma & $8.5 \pm 0.5270$ & $8.4 \pm 0.6992$ & $8.1 \pm 0.5676$ & $8.6 \pm 0.6992$ \\
\hline Flavour & $8.6 \pm 0.5163$ & $8.4 \pm 0.6992$ & $8.2 \pm 0.6324$ & $8.6 \pm 0.5163$ \\
\hline Texture & $8.6 \pm 0.6992$ & $8.1 \pm 0.8755$ & $8.2 \pm 0.4216$ & $8.8 \pm 0.4216$ \\
\hline Mouthfeel & $8.5 \pm 0.7071$ & $8.8 \pm 0.4216$ & $8.0 \pm 0.9428$ & $8.8 \pm 0.4216$ \\
\hline Chewiness & $8.3 \pm 0.6749$ & $8.4 \pm 0.5163$ & $8.4 \pm 0.5163$ & $8.7 \pm 0.4830$ \\
\hline Aftertaste & $8.4 \pm 0.6992$ & $8.8 \pm 0.4216$ & $8.1 \pm 0.7378$ & $8.9 \pm 0.3162$ \\
\hline
\end{tabular}

The values are means of ten replicates \pm standard deviation 


\subsubsection{Overall acceptability of cookies}

Overall acceptability is an important parameter in organoleptic estimation as it plays crucial role in decision making. Here figure 4 depicts the mean of 10 values taken in percentage. It shows a comparison between the overall acceptability of chocolate and vanilla flavoured cookies. It is clear from the figure that the chocolate flavoured cookies were liked more by the male students $(8.9 \pm 0.3162)$, also the t-test value (0.0119) shows that there was a significant difference between them.
The female students also liked the chocolate flavour $(8.6 \pm 0.5163)$ slightly more than vanilla $(8.4 \pm 0.5163)$ but there was no significant difference $(0.1717)$. The male teachers liked chocolate flavour $(8.8 \pm 0.4216)$ significantly more $(0.0025)$ than the vanilla flavour $(8.2 \pm 0.4216)$ but the female teaching faculty equally liked both the flavours and same can be seen in figure 4. In general, all the panel members gave positive responses for the composite flour cookies and also showed interest to buy them if available commercially.

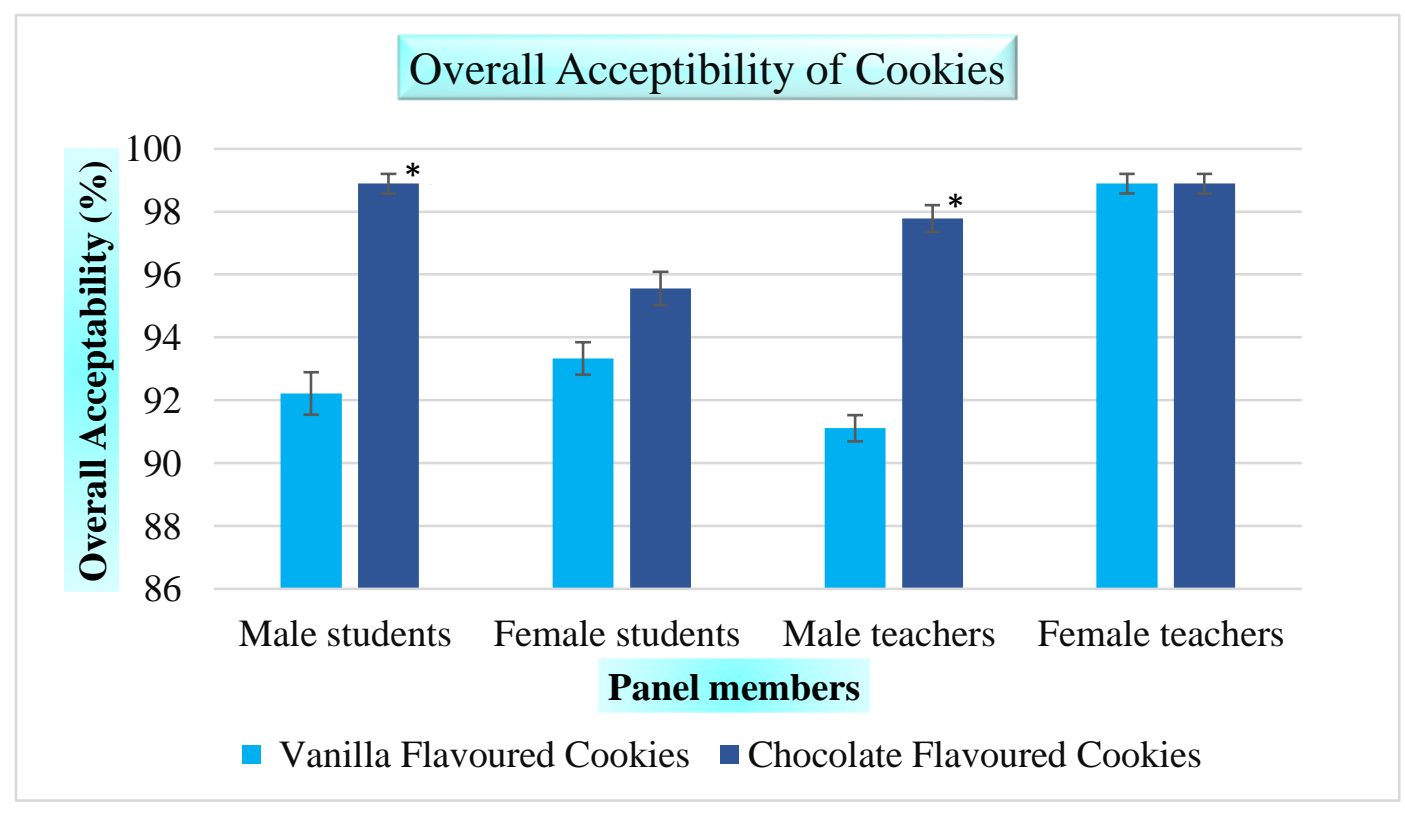

Fig 4: Showing overall acceptability of vanilla and chocolate flavoured cookies

Bar graph showing the percentage of mean values and error bars representing standard deviation.

*indicates that the values are significantly different i.e., $\mathrm{p}<0.05$ using the student t-test.

essential. Moreover, the effect of processing i.e., baking should also be studied.

\section{CONCLUSION}

The sensory evaluation proved that vanilla and chocolate flavoured cookies produced from the composite flour were accepted by majority of the respondents. These nutrient dense cookies can play an effective role in bringing down malnutrition. They will also be beneficial in reducing anaemia caused due to iron deficiency which fulfils the main objective of this research work. Thus, the production of these cookies at a commercial level will provide a good opportunity for entrepreneurship development.

\section{FUTURE PROSPECTIVE}

There is a need to study the anti-nutritional factors like phytates and oxalates as they are responsible for inhibiting iron absorption. The cookies should be given to anaemic patients and their haemoglobin levels need to be tested periodically to study the effectiveness of cookies in curing anaemia. A detailed analysis of the quality of proteins is also

\section{ACKNOWLEDGEMENT}

I would like to express my deep gratitude to our Chairperson Prof. Tharavati N.C. for her unconditional support and permission to carry out this project work in Food Science and Nutrition Department, Mangalore University, Mangalore, Karnataka.

\section{REFERENCES}

[1] Anilakumar, K. R., Pal, A., Khanum, F., \& Bawa, A. S. (2010). Nutritional, Medicinal and Industrial Uses of Sesame (Sesamum indicum L.) Seeds - An Overview. Agriculturae Conspectus Scientificus, 75(4), 159-168. https://www.researchgate.net/publication/50870025

[2] Awogbenja, M. D., \& Ndife, J. (2012). Evaluation of Infant Feeding and Care Practices Among Mothers in Nassarawa Eggon Local Government Area of Nasarawa State. Indian Journal of Science, 3(1), 21-29.

[3] Chandra, S., Singh, S., \& Kumari, D. (2015). Evaluation of functional properties of composite flours and sensorial attributes of composite flour biscuits. Journal of Food Science and 
Technology, 52(6), 3681-3688. https://doi.org/10.1007/s13197014-1427-2

[4] Dhingra, S., \& Jood, S. (2002). Organoleptic and nutritional evaluation of wheat breads supplemented with soybean and barley flour. Food Chemistry, 77(4), 479-488. https://doi.org/10.1016/S0308-8146(01)00387-9

[5] Guinard, J. X., \& Mazzucchelli, R. (1996). The sensory perception of texture and mouthfeel. Trends in Food Science and Technology, 7(7), 213-219. https://doi.org/10.1016/09242244(96)10025-X

[6] Handa, C., Goomer, S., \& Siddhu, A. (2012). Physicochemical properties and sensory evaluation of fructoligosaccharide enriched cookies. Journal of Food Science and Technology, 49(2), 192-199. https://doi.org/10.1007/s13197-011-0277-4

[7] Ho, L. H., \& Latif, N.W.A. (2016). Nutritional composition, physical properties, and sensory evaluation of cookies prepared from wheat flour and pitaya (Hylocereus undatus) peel flour blends. Cogent Food \& Agriculture, 2(1), 1-10. https://doi.org/10.1080/23311932.2015.1136369

[8] Hussein, H. M., Hussein, M. M., \& El-Damohery, S. T. (2006) The effect of natural formulated functional biscuits on elderly bone health. Journal of Medical Sciences, 6(6), 937-943. https://doi.org/10.3923/jms.2006.937.943

[9] Inyang, U. E., Effiong, C.F., \& Nyah, A. P. E. (2018). Physical Properties, Nutritional Composition and Sensory Evaluation of Cookies Prepared from Rice, Unripe Banana and Sprouted Soybean Flour Blends. International Journal of Food Science and Biotechnology, 3(2), 70-76. https://doi.org/10.11648/j.ijfsb.20180302.15

[10] Jemziya, M. B. F., \& Mahendran, T. (2015). Quality characteristics and sensory evaluation of cookies produced from composite blends of sweet potato (Ipomoea batatas $L$.) and wheat (Triticum aestivum L.) flour. Sri Lanka Journal of Food and Agriculture, 1(2), 23-30. https://doi.org/10.4038/sljfa.v1i2.16

[11] Khokhar, S., \& Chauhan, B. M. (2006). Antinutritional factors in Moth Bean (Vigna aconitifolia): Varietal differences and effects of methods of domestic processing and cooking. Journal of Food Science, 51(3), 541-860.

[12] https://doi.org/https://doi.org/10.1111/j.13652621.1986.tb13887.x

[13] Kumar, P., Yadava, RK., Gollen, B., Kumar, S., Verma, RK., Yadav, S. (2011). Nutritional Contents and Medicinal Properties of Wheat: A Review. Life Sciences and Medicine Research, 22(1), 1-10. http://astonjournals.com/lsmr

[14] Nambi, V.A., Eganathan, P., \& Philip, P. I. M. (2012). Proximate and Mineral Composition Analysis of Little Millet Collected from Some Millet Growing Areas in Tamil Nadu. Indian Journal of Plant Genetic Resources, 25(2), 189-191.

[15] Nasir, M., Siddiq, M., Ravi, R., Harte, J. B., Dolan, K. D., \& Butt, M. S. (2010). Physical quality characteristics and sensory evaluation of cookies made with added defatted maize germ flour. Journal of Food Quality, 33(1), 72-84 https://doi.org/10.1111/j.1745-4557.2009.00291.x

[16] Negi, A., Boora, P., \& Khetarpaul, N. (2001). Starch and protein digestibility of newly released moth bean cultivars: Effect of soaking, dehulling, germination and pressure cooking. Nahrung, 45(4), 251-254. https://doi.org/10.1002/1521 3803(20010801)45:4<251::AID-FOOD251>3.0.CO;2-V

[17] NITI Aayog (National Institution for transforming India). (2019) Anemia - Alert: Is the Government aiming for Cost-effective interventions? https://www.niti.gov.in/niti/content/anemia-alertgovernment-aiming-cost-effective-

interventions\#: :text=The $\% 20$ Anemia $\% 20$ Mukt $\% 20$ Bharat $\% 20$ f ocuses,to\%2032\%25)\%20by\%202022.\&text=NITI\%20Aayog\%2 0looks\%20forward\%20for,anemia\%20levels\%20in\%20upcoming $\% 20$ years

[18] Nwakalor, C. N. (2014). Sensory Evaluation of Cookies Produced from Different Blends of Wheat and moringa Oleifera Leaf Flour. International Journal of Nutrition and Food Sciences, 3(4), 307. https://doi.org/10.11648/j.ijnfs.20140304.21

[19] Park, K. (2017). Park's textbook of preventive and social medicine (24 $4^{\text {th }}$ ed.). Bhanot Publishers, 1-936

[20] Pradeep, S. R., \& Guha, M. (2011). Effect of processing methods on the nutraceutical and antioxidant properties of little millet (Panicum sumatrense) extracts. Food Chemistry, 126(4), 16431647. https://doi.org/10.1016/j.foodchem.2010.12.047

[21] Preethi, S. A. E., \& Mohankumar, J. B. (2014). Formulation and Acceptability Study of Micronutrient Rich Composite Flou Cookiesitle. Indian Journal of Research in Food Science and Nutrition, $\quad 1(2), \quad 7-11$ https://doi.org/10.15613/fijrfn\%2F2014\%2Fv1i2\%2F63068

[22] Policegoudra, R. S., Aradhya, S. M., and Singh, L. (2011). Mango ginger (Curcuma amada Roxb.) - A promising spice for phytochemicals and biological activities. Journal of Bioscience, 36(4), 739-748. https://doi.org/https://doi.org/10.1007/s12038011-9106-1

[23] Sadasivam, S. and Manickam, A. (1997). Biochemical methods. 2ndedn. New age international (p) Ltd. Publisher, New Delhi, 5 207

[24] Singh, S., Riar, C. S., \& Saxena, D. C. (2008). Effect of incorporating sweetpotato flour to wheat flour on the quality characteristics of cookies. African Journal of Food Science, 2(2008), 65-72. http://www.academicjournals.org/ajfs

[25] Varastegani, B., Zzaman, W., \& Yang, T. A. (2015). Investigation on physicochemical and sensory evaluation of cookies substituted with papaya pulp flour. Journal of Food Quality, 38(3), 175-183. https://doi.org/10.1111/jfq.12129 